УДК 911.375.5:712.2(470.325)

ПРОЦЕСС УРБАНИЗАЦИИ БЕРЕГОВЫХ ПРОСТРАНСТВ

СОВРЕМЕННОГО ГОРОДА (НА ПРИМЕРЕ БЕЛГОРОДСКОЙ ГОРОДСКОЙ АГЛОМЕРАЦИИ)

${ }^{1}$ Королева И.С., ${ }^{2}$ Королев А.С.

${ }^{1}$ ФГАОУ ВО «Белгородский государственный национальный исследовательский университет»,

Белгород, e-mail: koroleva_i@bsu.edu.ru;

${ }^{2}$ Национальный исследовательский университет «Высшая школа экономики», Москва

\begin{abstract}
Изучен отечественный и зарубежный опыт реорганизации и благоустройства береговых рекреационных пространств с позиции ландшафтного урбанизма. Родоначальником ландшафтного урбанизма считают Фредерика Олмстеда. В 1990-х гг. в Париже, Барселоне и Канберре появляются первые общественно-рекреационные пространства, спроектированные по принципам ландшафтного урбанизма. В настоящее время ландшафтный урбанизм применяют для реорганизации, реконструкции и рекреационного освоения территорий различного функционального назначения. Начиная с 1980 годов вектор развития ландшафтного урбанизма в Европе был устремлен в сторону формирования береговых пространств, поскольку единственной возможностью горожан на пребывание в комфортной среде с природными приоритетами являются городские набережные. В настоящее время продвижением такого направления в Европе занимается Мишель Девинь. В России ландшафтный урбанизм только начинает развиваться. Исследованиями в области ландшафтного урбанизма в нашей стране занимаются Э.Э. Красильникова, В.А. Нефедов и другие. Выявлены основные направления развития рекреационных пространств при реализации ландшафтно-градостроительного подхода и особенности их формирования на землях неблагоприятных для использования. Определены перспективы применения принципов ландшафтного урбанизма при реконструкции городских набережных. Проанализирована современная функционально-планировочная структура г. Белгорода с определением перспектив ее изменения с учетом принципов ландшафтного урбанизма и формирования единого эколого-рекреационного каркаса. Выявлены достоинства и недостатки проведенной реконструкции набережной реки Везелка и перспективы ее дальнейшей реконструкции с учетом концепций ландшафтного урбанизма и экогорода.
\end{abstract}

Ключевые слова: рекреационное пространство, ландшафтный урбанизм, озеленение, урбанизация, береговая зона

\title{
PROCESS OF URBANIZATION OF COASTAL SPACES OF THE MODERN CITY (ON THE EXAMPLE OF BELGOROD CITY AGGLOMERATION)
}

\author{
${ }^{1}$ Koroleva I.S., ${ }^{2}$ Korolev A.S. \\ ${ }^{1}$ Federal State Autonomous Educational Institution of Higher Education \\ «Belgorod State National Research University»,Belgorod, e-mail: koroleva_i@bsu.edu.ru; \\ ${ }^{2}$ National Research University «Higher School of Economics», Moscow
}

\begin{abstract}
Studied domestic and foreign experience of restructuring and improvement of coastal recreational spaces from the perspective of land-amenity and landscape benets of urbanism. The founder of landscape urbanism consider Frederick law Olmsted. In the 90-ies of XX century in Paris, Barcelona and Canberra appear the first public recreational space, constructed according to the principles of landscape urbanism. Currently, landscape urbanism applied to the reorganization, redevelopment and recreational use of territories of different functional purpose. Since 80 years the vector of development of landscape urbanism in Europe, was directed to the formation of coastal spaces, since the only ability of citizens to stay in a comfortable environment with the natural priorities are urban embankments. Currently, the promotion of such areas in Europe have been Michelle Devine. In Russia, the landscape urbanism only begins to develop. Research in the field of landscape urbanism in our country do E.E. Krasil'nikova, V.A. Nefedov and others. The main trends in the development of recreational spaces in the implementation of landscape and urban planning approach and the peculiarities of their formation on the lands are not favorable for use. The prospects for applying the principles of landscape urbanism in the reconstruction of urban waterfronts. Analyzed modern functional and planning structure of the city of Belgorod with determining the prospects for change based on the principles of landscape urbanism and the formation of a unified ecological and recreational framework. Identified the advantages and disadvantages of the reconstruction of the embankment of the river Veselka and prospects of its further reconstruction with the concepts of landscape urbanism and eco-city.
\end{abstract}

Keywords: landscape urbanism, recreational space, urban landscape, coastal complexes, attractors

В конце 1960 гг. человечество переосмыслило роль урбанизации в преобразовании пространства и ухудшении состояния здоровья людей. Это стало ядром, зародившим экологические направления в концептуальном виденье пространства городов. Их популяризация способствовала изменению облика европейских городов - около $50 \%$ территории были преобразованы в зеленые зоны. В настоящее время европейские сообщества, по мнению Т. Битли, предпочитают жить в городских районах «фундаментально встроенных в природную среду» $[1,2]$.

Одним из таких подходов в современном мире является ландшафтный урбанизм, направленный на создание экологически 
безопасной территории, включенной в природную среду, в которой сбалансированы и взаимосвязаны социальная, экономическая и экологическая сферы. В нем в качестве связующего звена всех сфер выступает система озеленения, создающая сложные функциональные связи между системами озелененных транспортных пространств, городскими рекреационными зонами и озелененным пространством жилых комплексов и архитектурных объектов. Ранее, согласно теории Ф.Л. Олмстеда, в качестве озелененного пространства, обеспечивающего комфортность среды, был парк, теперь - это крупные природные элементы, как правило, реки - способные обеспечить дальнейшее спонтанное развитие пространства и включенные в природную среду.

Цель исследования - изучение современного уровня формирования и развития городских набережных в условиях ландшафтного урбанизма (на примере г. Белгорода). Основные задачи исследования: изучение отечественного и зарубежного опыта реорганизации и реконструкции береговых рекреационных пространств с позиции ландшафтного урбанизма, оценка современного состояния развития рекреационных пространств Белгородской агломерации и функционально-планировочной структуры г. Белгорода с определением перспектив ее изменения и создания, реконструкции городских набережных в г. Белгороде с применением принципов ландшафтного урбанизма.

Методы исследования: ландшафтный урбанизм и ландшафтно-рекреационное проектирование, способствующие единению человека с природой посредством формирования рекреационно-комфортного ландшафта.

Родоначальником ландшафтного урбанизма считают Ф. Олмстеда. Его идеи и концепции до сих пор являются основополагающими в рекреационном проектировании и ландшафтном дизайне. К принципам ландшафтного урбанизма относят: единство ландшафта и архитектуры, функциональную двойственность, подземную интеграцию, толерантность к окружающей среде, изменчивость во времени. Наиболее широкое распространение ландшафтный урбанизм получил в начале XXI века в европейских городах. В этот период его развитием занимались С. Waldheim, J. Corner и M. Mostafavi [3], Б. Чуми, Р. Коолхааса. В 90-х годах XX века в Париже, Барселоне и Канберре появляются первые общественно-рекреационные пространства, спроек- тированные по принципам ландшафтного урбанизма.

Начиная с 1980 гг. вектор развития ландшафтного урбанизма, в Европе, был устремлен в сторону формирования береговых пространств, поскольку единственной возможностью горожан на пребывание в комфортной среде с природными приоритетами являются городские набережные. В настоящее время продвижением такого направления в Европе занимается М. Девиня. Исследованиями в области ландшафтного урбанизма в России занимаются Э.Э. Красильникова, В.А. Нефедов и другие [4].

Учитывая зарубежный и отечественный опыт формирования береговых пространств, основанный на концепции ландшафтного урбанизма, можно выделить следующие направления повышения качества среды: озеленение прибрежных территорий с целью эстетической гармонизации пространства и регулирования климата, экореконструкция городских набережных и регенерация прибрежных постпромышленных территорий с применением натуральных материалов, расширение береговой и аквальной инфраструктур (мест досуга, публичных пространств, стоянок для водного транспорта), создание среды с «контактной» водой и мобильных компонентов в водной среде с привлечением инвестиций, энергоэффективность зданий и создание условий для использования набережных в темное время суток, сбалансированное развитие пешеходной, велосипедной и транспортных инфраструктур, восстановление аквальных и береговых комплексов с целью поддержания экологического равновесия. Данные принципы позволяют провести функциональную и ландшафтную оптимизацию структур береговых территорий, сформировать единый водно-зеленый каркаса города и достичь идентичности набережных [5].

Д. Парамонова отмечает, что в настоящее время принципы ландшафтного урбанизма применяются в 40 городах Российской Федерации. Одним из таких городов является г. Белгород.

\section{Результаты исследования и их обсуждение}

Поскольку процесс формирования городской среды, основанной на принципах ландшафтного урбанизма, должен начинаться с создания взаимосвязанной системы озелененных транспортных пространств, городских общественных парков, скверов, площадей, пешеходных улиц, набережных 
и заканчиваться формированием внутренних пространств жилых комплексов, то необходимо проанализировать существующую систему озеленения городского пространства. Функционально-планировочная структура г. Белгорода складывалась исторически и несёт в себе следы всех прошедших эпох, объединяя достоинства и недостатки методов формообразования городских систем каждой исторической эпохи. В результате всех этих преобразований удельный вес озелененной территории г. Белгорода составляет $31,5 \%$, что на $8,5 \%$ ниже принятой нормы. В то же время отмечается диспропорция в структуре функциональных зон г. Белгорода. Соотношение между производственной, селитебной и рекреационной территориями составляет, соответственно $11,2 \%-18,9 \%-11,4 \%$ $(1: 1,7: 1)$ вместо 1:2:3 [6]. Согласно Генеральному плану развития городского округа «Город Белгород» до 2025 г. доля рекреационных территорий достигнет 14,7\%, а соотношение между функциональными зонами города будет составлять 1:2,3:1,2. Таким образом, и в 2025 г. останется актуальной проблема увеличения доли рекреационных зон в 3 раза. Достичь увеличения доли рекреационных зон планируют за счет формирования рекреационных зон в пригородной лесопарковой зоне, рекреационного обустройства промышленных районов города. В связи с этим целесообразно рассматривать рекреационные зоны не только г. Белгорода, но и всей агломерации.

Современная система озеленения Белгородской агломерации представлена зелеными насаждениями: общего, ограниченного пользования и специального назначения. Согласно плану развития Белгородской агломерации рекреационные зоны будут формироваться преимущественно в Шебекинском и Борисовском районах, а Белгородский и Корочанский районы станут поставщиками экологически чистых продуктов питания. В соответствии с постановлением Правительства Белгородской области «О территориях рекреационного назначения» от 2.06.2008 г. № 133-пп (с изменениями на: 22.09.2014) к территориям рекреационного назначения относятся особо охраняемые природные территории. В границах Белгородской агломерации, в соответствии с постановлением Правительства Белгородской области «Об утверждении перечня особо охраняемых природных территорий регионального значения Белгородской области» от 15.08.2016 г.
№ 299-пп в границах 1,5-часовой транспортной доступности, находится 14932,2 га природных парков включенных в состав особо охраняемых природных территорий. На землях рекреационного назначения в 2016-2017 гг. были созданы такие аттракторы, как сельский парк «Русская деревня» (с. Шагаровка), манеж для тренинга лошадей (с. Нижний Ольшанец), Белгородский зоопарк, экзотариум, аквапарк и динопарк в «Мультипарке «Белгородский» (урочище Сосновка). Данный рекреационный аттрактор размещается на левом берегу реки Северский Донец, в наиболее рекреационно привлекательной зоне. В настоящее время площадь территории формирующегося мультипарка составляет 1230,5 га. В то же время осуществляется обустройство Центрального парка культуры и отдыха, парка «Победы», планируется создание «Гребного канала», парковой зоны отдыха в вдоль трассы М2 «Крым», туристической рекреационной зоны «Хрустальная долина» и других. Таким образом, существующие и создаваемые рекреационные зоны Белгородской агломерации тяготеют к таким природным образованиям, как реки Ворскла, Северский Донец и ее притоки. Правый приток реки Северский Донец является ключевым элементом водного эколого-рекреационного каркаса г. Белгорода, разделяющим город на две части. Река Везелка имеет на всем своем протяжении контрастные эстетикорекреационные пейзажи - от берегов, поросших травой до каменных. Рекреационно освоенными территориями до 2017 г. были участки от ул. Победы до ул. Попова - парки «Победа» и «Котофей», площадь трех музеев.

Первые попытки преобразования реки Везелка были начаты в 2007 г. Ее целью было создание открытой прогулочной зоны с искусственным освещением и чугунными перилами (рис. 1, а). При проектировании набережной реки Везелка (площадка спортивного комплекса Светланы Хоркиной) не были учтены природные факторы (зной и ветер), а дискомфортные условия не позволили этой эстетически привлекательной территории стать популярным местом отдыха белгородцев. Недостатком открытых пространств долин является отсутствие естественных укрытий от природных факторов. Вторая каменная набережная была построена в 2016 г. напротив площади трех музеев, что привело к эстетическо-рекреационной дисгармонии пространства (рис. 1, б). 


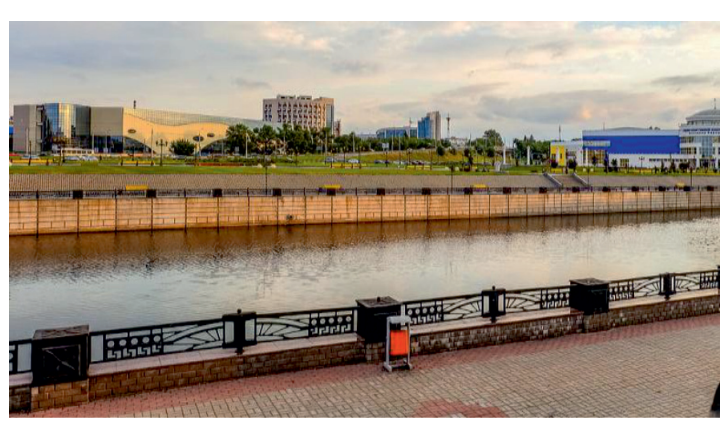

$a$

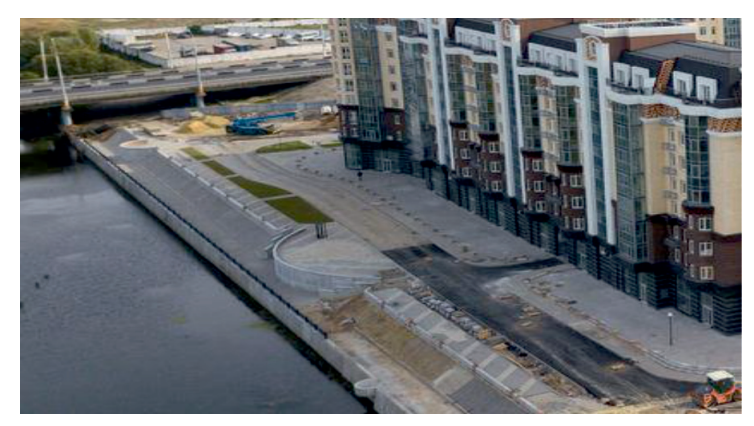

$\sigma$

Рис. 1. Бетонные набережные реки Везелка: $а$ - у спортивного комплекса С. Хоркиной, б - ужилого комплекса «Париж»

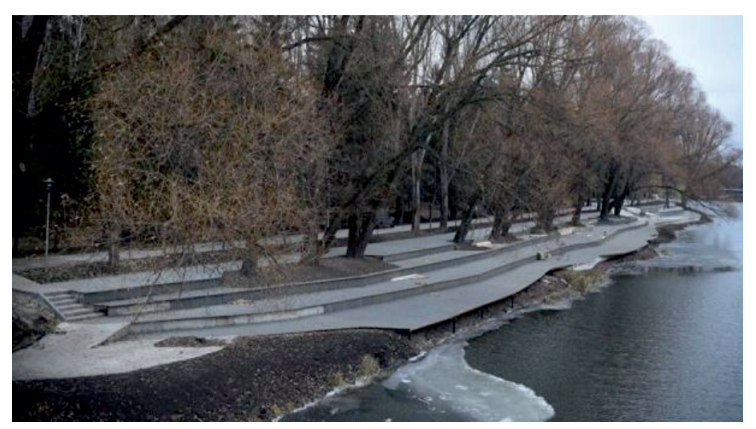

$a$

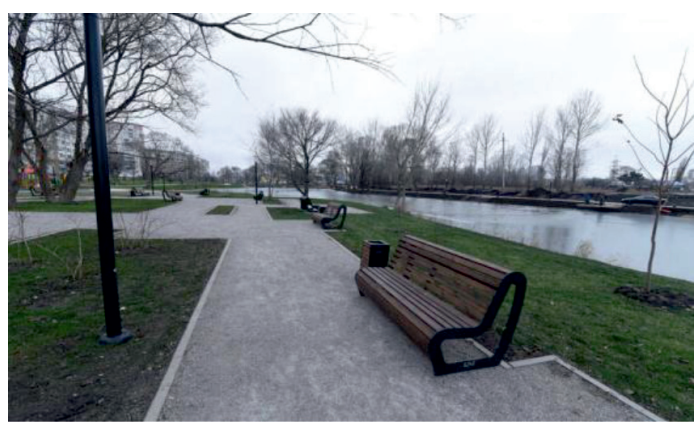

$\sigma$

Рис. 2. Реконструкиия Белгородской набережной: а - деревянное мощение в парке «Победа», б - ошибки в планировочной организации рекреационного пространства набережной р. Везелка

Необходимость обустройства и реконструкции побережья реки Везелка появилась уже давно. Во-первых, это обусловлено тем, что с 1990 гг. на правом берегу реки Везелка рядом с зоопарком находилась заброшенная рекреационная зона (2 га), с 2013 г. - парк «Котофей». Во-вторых, береговые и аквальные комплексы парка «Победа» испытывают значительные рекреационные нагрузки, приведшие к изменению почво-растительных комплексов, появлению участков с абразионно-береговыми склонами и деградации ландшафта [7].

В 2017 г. управление архитектуры и градостроительства Белгородской области совместно с конструкторским бюро «Стрелка» проведена реконструкция 3 участков набережной реки Везелки. Д. Парамонова отмечает, что перед проведением проектных работ был проведен комплексный анализ территории, позволивший выявить зоны необходимые для жителей - прогулочная, спортивная и развлекательная.
В результате проведенной реконструкции Белгородская набережная приобрела свою идентичность:

- появились среда с «контактной» водой (рыбацкие мостики, террасы и прогулочные площадки), условия для использования набережной в темное время суток, сбалансированность между пешеходной и велосипедной инфраструктурой;

- была проведена регенерация прибрежной промышленной зоны «Конпрок» с применением вертикального озеленения и парковой зоны с использованием натуральных материалов (деревянное мощение) (рис. 2, а). Данный прием позволяет укреплять откосы и создавать эстетически привлекательный внешний вид;

- созданы береговая и аквальная инфраструктуры.

Анализ теоретического и практического опыта отечественных и зарубежных исследований по реконструкции набережных рек, программы реконструкции р. Везелка, обна- 
родованной на пресс-конференции, и материалов ее обследования позволил выявить недостатки проведенной реконструкции: К ним можно отнести: отсутствие на всем протяжении береговой зоны регенеративных, мелиоративных и сукцессионных работ, направленных на озеленение прибрежных территорий, вырубку деревьев вдоль береговой линии, ошибки в планировочной организации рекреационного пространства (без учета видовых точек) (рис. 2, б).

Поскольку город это динамичная изменяемая система под запросы потребителей, то и набережные должны изменяться, сохраняя свою целостность. В связи с этим для реализации принципов ландшафтного урбанизма и устранения допущенных ошибок необходимо провести мероприятия направленные на оздоровление и повышение аттрактивности береговых и аквальных комплексов:

1) ликвидировать несанкционированные сбросы в реку Везелка,

2) провести лесо- и лугомелиоративные работы путем последовательного замещения старой растительности многолетними устойчивыми к выкатыванию травами и высадкой древесно-кустарниковых пород, направленные на берегоукрепление, создание визуальных разделительных барьеров, реструктуризации и озеленение пространства у спортивного комплекса С. Хоркиной, в промышленной зоне и прилегающих территориях,

3) использовать фиторемедитацию и другие экологические способы очистки воды для восстановления водной флоры и фауны,

4) закрыть в районе парка улицу Попова для движения транспорта и сократить площадь наземных парковок,

5) обеспечить энергоэффективность зданий.

\section{Выводы}

1. Тенденции развития городов, последних лет направлены на создание благоприятных условий для жизни в урбанизированном ландшафте и очистку окружающей природной среды в городских пространствах. Реализация данных тенденций осуществляется через разработку новой пространственной структуры «городов-ландшафтов», или реорганизацию существующей структуры, в которых экологическая и ландшафтная составляющая является главенствующей.

2. Рекреационные территории в функционально-планировочной структуре город- ской среды являются частью ландшафтной инфраструктуры города, обеспечивающей устойчивость всего городского пространства. А современные городские пространства, организованные с учетом принципов ландшафтного урбанизма в структуре крупных городов имеют ярко выраженное общественно-рекреационное значение, что соответствует современным градостроительным регламентам - SCOT и SRU.

3. В соответствии с отечественным и зарубежным опытом, набережные являются основными осями роста городов, выступающими в качестве эффективных барьеров и обеспечивающими целостность природной и урбанизированной систем, условия для качественной и полноценной жизни, то при их реконструкции необходимо стремиться к сохранению и восстановлению природной среды.

4. Поскольку ландшафтный подход позволяет обеспечить необходимую географическую связанность территории, защитить городские системы от стихийных бедствий (штормов, наводнений и других), то восстановление и реконструирование береговых и аквальных комплексов рек Везелка и Северский Донец позволит не только сформировать единые рекреационное пространство и водно-рекреационный каркас с целью устойчивого развития территории, но и защитить территории от подтоплений и будет способствовать оздоровлению населения.

\section{Список литературы}

1. Красильникова Э. Ландшафтный урбанизм: новый взгляд на старую проблему [Электронный ресурс]. - URL: http:/green-city.su/landshaftnyj-urbanizm (дата обращения: 10.01.2018).

2. Логунова Е.Н. Ландшафтный урбанизм как метод формирования экологического сознания [Электронный реcypc]. - URL: http://elib.sfu-kras.ru/handle/2311/11985 (дата обращения: 10.01.2018).

3. Gintoff Vladimir. Projects that Explain Landscape Urbanism and How its changing the face of cities. ArchDaily [Электронный ресурc]. - URL: https://www.archdaily.com (дата обращения: 10.01.2018).

4. Красильникова Э.Э. Современный ландшафтно-градостроительный подход к созданию городских общественно-рекреационных территорий. - Проект Нижняя Волга. 2013. - № 4. - С. 26.

5. Красильникова Э.Э. Перспективы развития прибрежных общественно-рекреационных территорий / Э.Э. Красильникова, О.С. Данилина, М.А. Прохорова, Н.П. Яровая // Сборник Международной конференции, посвященной 80-летию строительного образования и 40-летию архитектурного образования Волгоградской области: «Наука и образование: архитектура, градостроительство и строительство». - 2010. - С. 382-384.

6. Полякова Т.А. Состояние и оценка функционально-планировочной структуры крупного города: на примере г. Белгорода: автореф. дис. ... канд. географ. наук. - Краснодар, 2011. - 23 с.

7. Лозовая С.Ю. Анализ затоплений урбанизированных территорий Белгородской области с использованием 
геоинформационных систем и технологий / С.Ю. Лозовая, Н.М. Лозовой, В.В. Смолярчук, А.Э. Трунова // Наука и образование сегодня. - 2017. - № 9 - С. 63-67.

\section{References}

1. Krasil'nikova E. Landshaftnyi urbanizm: novyi vzgliad na staruiu problemu [Landscape urbanism: a new look at an old problem]. Available at: http://green-city.su/landshaftnyj-urbanizm (accessed 10.01.2018)

2. Logunova E.N. Landshaftnyi urbanizm kak metod formirovaniia ekologicheskogo soznaniia [Landscape urbanism as a method of formation of ecological consciousness]. Available at: http://elib.sfu-kras.ru/handle/2311/11985 (accessed 10.01.2018).

3. Gintoff Vladimir. Projects that Explain Landscape Urbanism and How it,s changing the face of cities. ArchDaily. Available at: https://www.archdaily.com (accessed 10.01.2018).

4. Krasil'nikova E.E. Sovremennyi landshaftnogradostroitel'nyi podkhod k sozdaniiu gorodskikh obshchestvenno-rekreatsionnykh territorii. - Proekt, Nizhniaia Volga. 2013. No. pp. 26. [Modern landscape-urban approach to creating urban public recreational areas. Project The Lower Volga. 2013. No. 4 pp. 26.]. Proekt Nizhniaia Volga [Project The Lower Volga. 2013. No. 4. pp. 26.]. Volgograd, 2013, pp. 26.
5. Krasil'nikova E.E., Danilina O.S., Prokhorova M.A., Iarovaia N.P. Perspektivy razvitiia pribrezhnykh obshchestvenno-rekreatsionnykh territorii [Krasilnikova E.E. prospects of development of the coastal public recreational areas]. Mezhdunarodnaia konferentsiia nauka i obrazovanie: arkhitektura, gradostroitelstvo i stroitel"stvo (g. Volgograd, 6-10 sentiabria 2010 g.) [Proceedings of international conference «Science and Education: Architecture, urban planning and construction» (Volgograd, September 6-10, 2010)], Volgograd state University of architecture and civil engineering, Volgogradskii gosudarstvennyi arkhitekturno-stroitel'nyi universitet, 2010, pp. 382-384.

6. Poliakova T.A. Sostoianie i otsenka funktsional'no-planirovochnoi struktury krupnogo goroda: na primere g. Belgoroda [State and evaluation of the functional-planning structure of a large city (by the example of Belgorod)]. avtoref. na soiskanie stepeni k.g.n. Krasnodar, 2011, 23.

7. Lozovaia S.Iu., Lozovoi N.M., Smoliarchuk V.V., Trunova A.E. Analysis of flooding of urban areas of the Belgorod region with the use of geographic information systems and technologies [Analiz zatoplenii urbanizirovannykh territorii Belgorodskoi oblasti s ispol'zovaniem geoinformatsionnykh sistem i tekhnologii]. Nauka i obrazovanie segodnia - Science and education today, 2017, no. 9, pp. 63-67. 